\title{
Difference in enzymatic dehydrogenative polymerization of dilignols using horseradish peroxidase and crude enzyme obtained from Japanese cypress (Chamaecyparis obtusa)
}

\author{
Yasuyuki Matsushita* ${ }^{*}$, Daisuke Baba, Dan Aoki and Kazuhiko Fukushima
}

\begin{abstract}
Lignin is a biopolymer consisted of monolignols but the growth mechanism of lignin has not yet been elucidated. In this study, enzymatic dehydrogenative polymerization of dilignols, guaiacylglycerol- $\beta$-coniferyl ether (I), dehydrodiconiferyl alcohol (II), and pinoresinol (III), was conducted using crude enzyme obtained from Japanese cypress (Chamaecyparis obtusa) in order to investigate the step following the initial radical coupling between monolignols. The results suggested the occurrence of radical transfer during the reaction, similar to the reaction using horseradish peroxidase (HRP). The behavior of erythro and threo of I during the reaction was analyzed, and it was found that the crude enzyme has a substrate specificity toward erythro rather than threo forms, but HRP shows negligible specificity. And that erythro of I shows a slightly greater tendency to form a radical by radical transfer from II or III than the threo form.
\end{abstract}

Keywords: Lignin, Dehydrogenative polymerization, Radical transfer, Enzyme, Substrate specificity

\section{Introduction}

Lignin is a natural polymer comprising monolignol as the monomer unit. The polymerization mechanism for lignin formation is unique. The first step of the polymerization, radical coupling, proceeds between two monolignol radicals generated by enzymatic oxidation to yield mainly three dilignols, guaiacylglycerol- $\beta$-coniferyl ether (I), dehydrodiconiferyl alcohol (II), and pinoresinol (III), which have $\beta-O-4, \beta-5$, and $\beta-\beta$ linkages, respectively. These radicals are consumed after the first step, and hence, new dilignol radicals must be generated for the growth of the polymer chain. Lignin is thought to grow by the repeated formation of monolignol, oligolignol, and polylignol (i.e., lignin) radicals and subsequent coupling between two radicals. However, the steric hindrance at the attachment between the enzyme and the oligo- or polylignol would make it difficult to oxidize

*Correspondence: ysmatsu@agr.nagoya-u.ac.jp

Graduate School of Bioagricultural Sciences, Nagoya University, Furo-cho Chikusa-ku, Nagoya, Aichi 464-8601, Japan them. Recently, a specific enzyme for lignin growth was proposed; the redox-active sites are located on the protein surface, resulting in the except the considering of the steric hindrance [1-3]. A radical transfer model was also proposed, according to which the monolignol radical site is transferred to the oligo- or polylignol, which led to generate the corresponding radical [4]. In this hypothesis, the monolignol plays the role of a redox shuttle. In addition, a radical transfer system between coniferyl alcohol and sinapyl alcohol [5-8], $p$-coumarate and sinapyl alcohol $[9,10]$, superoxide radical in the presence of calcium and coniferyl alcohol [11], and manganese oxalate and monolignols [12] were reported. Previously, we investigated the enzymatic oxidation of dilignols using horseradish peroxidase (HRP) and proposed a radical transfer system, where one dilignol radical transfers its radical site to another dilignol $[13,14]$.

HRP is generally used for studies on lignin, but it is not obtained from woody plants. It is unclear that the enzyme from woody plants acts the same reaction as HRP. In this research, we used the crude enzyme obtained from 
the differentiating xylem of Japanese cypress (Chamaecyparis obtusa) to investigate the chain growth from dilignols and shed light on the difference between the polymerization modes observed in the presence of HRP and this crude enzyme.

\section{Materials and methods Materials}

Compounds I, II, and III were synthesized according to the method in our previous study [13, 14]. Briefly, after the oxidation of coniferyl alcohol by silver (I) oxide, these three compounds were isolated by flash column chromatography (Agilent 971-FP, Agilent Technologies) using a silica gel column (Super Flash SF, Agilent Technologies). HRP was purchased from Wako Pure Chemical Industries.

\section{Crude enzyme extraction}

The crude enzyme was isolated using the method reported by Hiraide et al. [15]. After debarking, the differentiating xylem was scraped off using a peeler and frozen by immersing in liquid nitrogen. The frozen differentiating xylem was ground into powder using a mortar cooled with liquid nitrogen.

Benzylsulfonyl fluoride (PMSF; $17.4 \mathrm{mg}$ ) was dissolved in $1 \mathrm{~mL}$ of dehydrated ethanol to prepare a $100 \mathrm{mM}$ PMSF EtOH solution. Polyvinyl pyrrolidone (PVP; $200 \mathrm{mg}$ ) was dissolved in $100 \mathrm{~mL}$ of $50 \mathrm{mM}$ acetic acid buffer ( $\mathrm{pH} 5.0$ ). To the PVP solution, $35 \mu \mathrm{L}$ of 2-mercaptoethanol, $500 \mu \mathrm{L}$ of PMSF ethanol solution, and $15 \mathrm{~g}$ of calcium chloride dihydrate were added to obtain an extraction buffer for soluble proteins. The prepared buffer was stored at $4{ }^{\circ} \mathrm{C}$.

The powdered frozen differentiating xylem was extracted using the solution buffer at $4{ }^{\circ} \mathrm{C}$ for $24 \mathrm{~h}$ to obtain the crude enzyme. After extraction, the buffer was dialyzed to remove calcium chloride using $50 \mathrm{mM}$ acetate buffer ( $\mathrm{pH}$ 5.0). To concentrate the protein, the dialyzed solution was centrifugated using an ultrafiltration tube (Amicon Ultra-15 mL, Merck Millipore, Darmstadt, Germany) at $3500 \mathrm{rpm}$ and $4{ }^{\circ} \mathrm{C}$.

\section{Enzyme activity}

The procedure for estimating the enzyme activity was based on our previous report [13], and the activity was determined from the oxidation rate of guaiacol. The activities of HRP and the crude enzyme obtained from cypress were 387.2 and $5.24 \mathrm{U} / \mathrm{mg}$, respectively.

\section{Enzymatic dehydrogenative polymerization}

Enzymatic dehydrogenative polymerization was carried out by a modification of our previously reported method
[13]. In this study, we employed two systems: a singlecomponent system and mixed-component system.

\section{Single-component system}

A solution of the dilignol substrate I, II, or III $(1.5 \mu \mathrm{mol}$ in $10 \mathrm{~mL}$ of distilled water) was subjected to enzymatic dehydrogenative polymerization catalyzed by the crude enzyme $(0.2 \mathrm{U})$ or HRP $(0.4 \mathrm{U})$ using $\mathrm{H}_{2} \mathrm{O}_{2}(0.125 \mu \mathrm{g})$. At certain times, a $0.3 \mathrm{~mL}$ aliquot was withdrawn from the reaction mixture and poured into catalase aqueous solution $(100 \mu \mathrm{L}$ of $0.01 \mathrm{mg} / \mathrm{mL})$ to stop the enzymatic reaction. The solution mixture was dried under reduced pressure, and the residue was dissolved in methanol $(150 \mu \mathrm{L})$. The samples were then prepared by membrane filtration (PTFE $0.50 \mu \mathrm{m}$, DISMIC-13JP, ADVANTEC), and liquid chromatography (LC) analysis was conducted. All experiments were performed in triplicate.

\section{Mixed-component system}

A mixture of two different dilignols $(\mathbf{I}+\mathbf{I I}, \mathbf{I}+\mathbf{I I I}$, and II + III; $0.75 \mu \mathrm{mol}+0.75 \mu \mathrm{mol}$ ) was subjected to enzymatic dehydrogenative polymerization similar to the case of the single-component system. All experiments were performed in triplicate.

\section{Liquid chromatography (LC) analysis}

LC analysis was carried out according to our previous study [14]. The LC system was composed of an Agilent 1100 series binary pump, an Agilent 1100 series variable wavelength detector, a column compartment, an Agilent 1260 Infinity high-performance degasser, and an Agilent 1200 series high-performance autosampler (Agilent Technologies Inc, USA). The equipment was fitted with a Luna phenyl-hexyl column (liquid layer thickness: $5 \mu \mathrm{m}, 150 \mathrm{~mm} \times 2.0 \mathrm{~mm}$, Phenomenex, USA). Ultrapure water (solvent A) and a methanol/acetonitrile $(6: 1, \mathrm{v} / \mathrm{v}$; solvent $\mathrm{B})$ mixture served as the mobile phase $(0.2 \mathrm{~mL} / \mathrm{min})$. The column temperature was $40{ }^{\circ} \mathrm{C}$. The elution gradient program was as follows: $0-4 \mathrm{~min}, 20 \%$ of B; 4-10 min, linear gradient from 20 to $30 \%$ of B; $10-15 \mathrm{~min}, 30 \%$ of B; $15-40 \mathrm{~min}$, linear gradient from 30 to $50 \%$ of $\mathrm{B} ; 40-80 \mathrm{~min}$, linear gradient from 50 to $60 \%$ of B; $80-90$ min, linear gradient from 60 to $20 \%$ of B. Substrate determination was performed at $280 \mathrm{~nm}$.

The erythro and threo peaks in the chromatogram of $\mathbf{I}$ were identified based on the LC analysis of erythro-rich $\mathbf{I}$.

I (erythro): retention time (RT): 24.9 min, I (threo): RT: $23.1 \mathrm{~min}$, II: RT: $36.1 \mathrm{~min}$, III: RT: $43.0 \mathrm{~min}$.

\section{Results and discussion \\ Enzyme activity against dilignols}

The enzyme activity against dilignols for HRP and the crude enzyme was investigated. II was selected as the 
dilignol. Although the same activity dosage $(0.4 \mathrm{U})$ against guaiacol was added for both enzymes, the consumption rate of II was higher when the crude enzyme was used (Additional file 1: Figure S1). This suggested that the crude enzyme contained many types of phenol oxidase. Accordingly, the experiments in this study were performed by reducing the crude enzyme dosage. The dosages of both enzymes were determined based on their activity against guaiacol: crude enzyme, $0.2 \mathrm{U}$; HRP, $0.4 \mathrm{U}$.

\section{Consumption rate of dilignols}

In our previous studies [13, 14], when HRP was used for the enzymatic dehydrogenative polymerization of dilignol, the consumption rate of I was the lowest among three dilignols. However, the consumption rate of I increased when another type of dilignol was mixed, i.e., when using a mixed-component system of $\mathbf{I}+\mathbf{I I}$ and I+ III, while the consumption rates of II and III decreased. In the case of the II+ III system, the consumption rate of II decreased but that of III increased. These results indicated a radical transfer system, where the radical form of II transfers its radical site to I or III, and the radical form of III transfers its radical site to $\mathbf{I}$.

In this study, we used the crude enzyme obtained from Japanese cypress to investigate the difference in polymerization mechanism against HRP. Figure 1 shows the residual ratio of dilignol in the single- and mixed-component system when using the crude enzyme. A similar trend in the consumption rate was seen when HRP was used, which implied that the same radical transfer

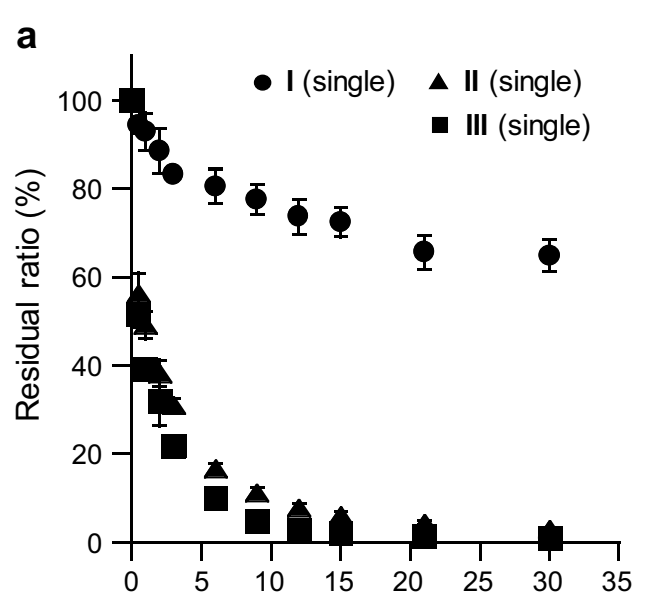

b
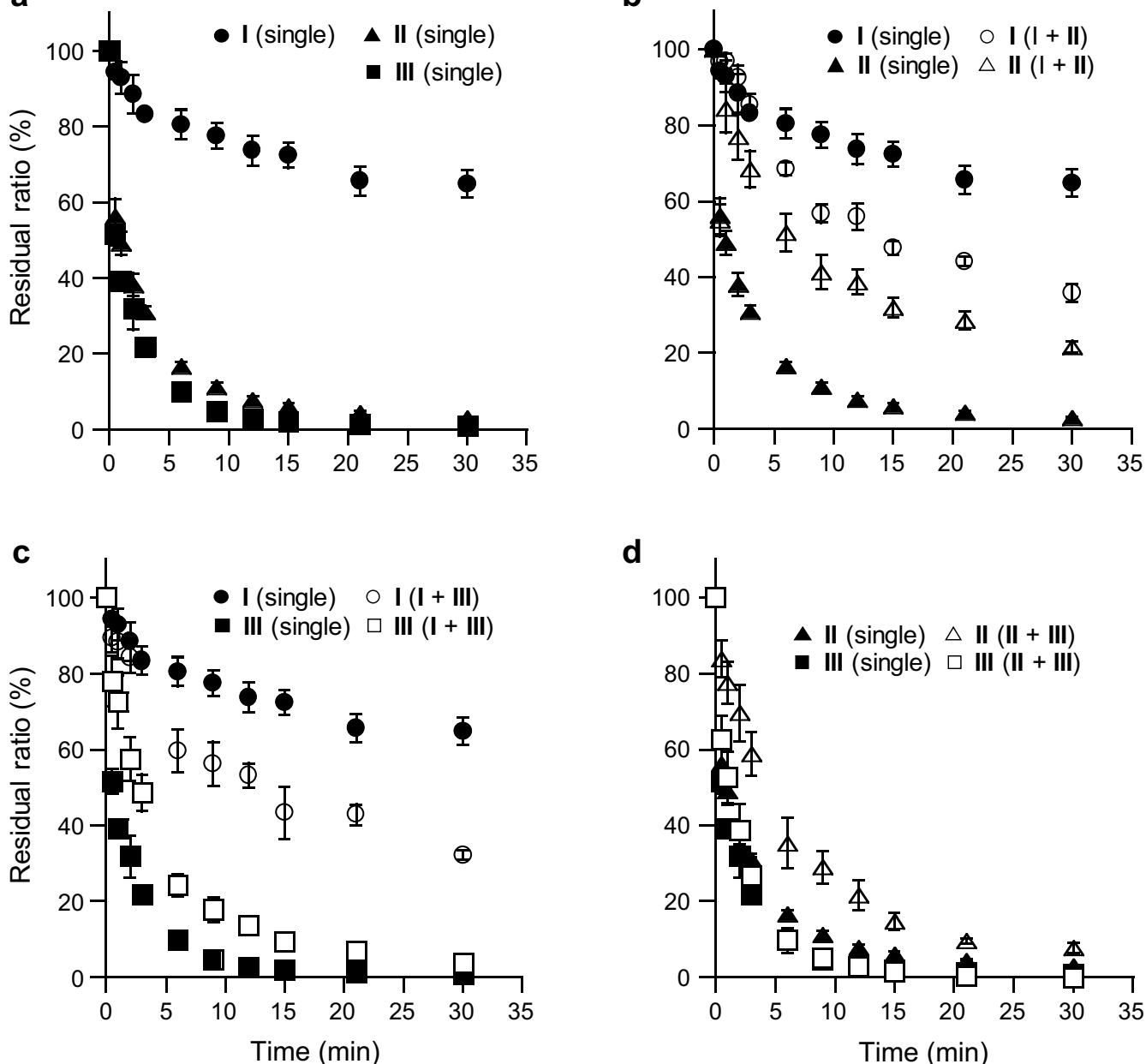

d

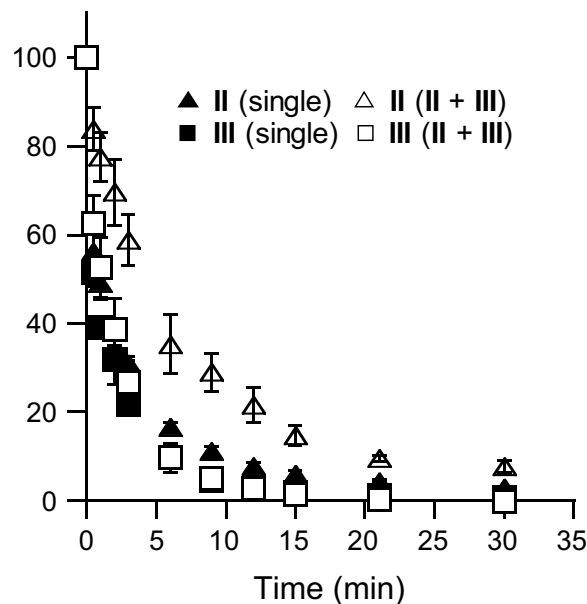

Fig. 1 Time course of residual ratio of the dilignols in the single-component and mixed-component systems. a Single-component system, $\mathbf{b}$ mixed-component system (I+ II), c mixed-component system (I+ III), d mixed-component system (II + III) b-d. Those in the single-component reactions were each described on a same figure for reference 


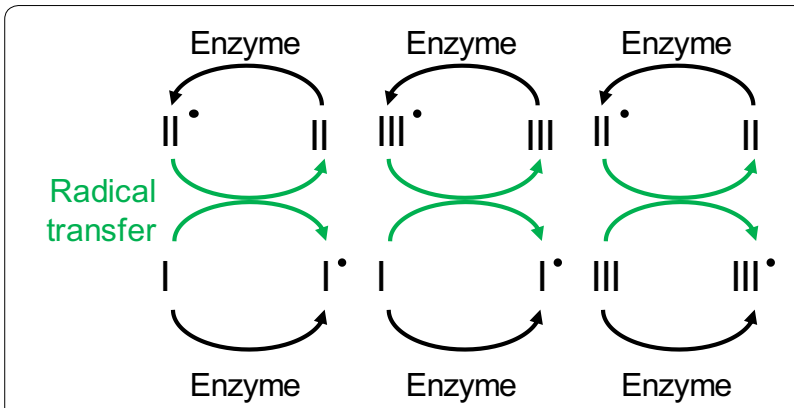

Fig. 2 Radical transfer system between dilignols. Enzyme: the crude enzyme and HRP

process occurred during the dehydrogenative polymerization using the crude enzyme (Fig. 2).

\section{Difference in consumption rates between erythro and threo isomers of I}

I has two types of diastereomers, erythro and threo. The erythro ratio (erythro/(erythro +threo)) in residual $\mathbf{I}$ is shown in Fig. 3. Additional file 1: Figure S2 shows the consumption rates of the erythro and threo forms of I. In the single-component system, when HRP was used, the erythro ratio was initially $53.2 \%$ and remained at the same level during the reaction $(53.6 \%$ at $30 \mathrm{~min})$. In the case of the mixed-system, the erythro ratio slightly decreased during the course of the reaction. This suggested that the erythro form shows a slightly greater tendency to form a radical by radical transfer from II or III than the threo form. One of the reasons why the II and III radicals preferentially reacted with erythro of I was thought to be the less steric hindrance around phenolic hydroxide of erythro form than that of threo form (Additional file 1: Figure S3). However, it is difficult to state the reason clearly. Further studies are necessary to prove the reasons.

On the other hand, when the crude enzyme was used, a greater amount of the erythro form was consumed as compared to the threo form in the single-component system (erythro ratio decreased from the initial value of 53.6 to $49.7 \%$ at $30 \mathrm{~min}$ ). This implied that the crude enzyme has a substrate specificity toward erythro rather than threo forms. The consumption trend became notable in the mixed-component system: in the mixture with II, the erythro ratio decreased from the initial value of 61.1 to $51.1 \%$ at $30 \mathrm{~min}$; in the mixture with III, the erythro ratio decreased from the initial value of 60.7 to $53.2 \%$ at $30 \mathrm{~min}$. This result was due to the combination of the substrate specificity of the crude enzyme and the ease of radical transfer from II or III to the erythro diastereomer.

In almost native softwood lignin, the proportions of erythro and threo were very similar [16]. However,

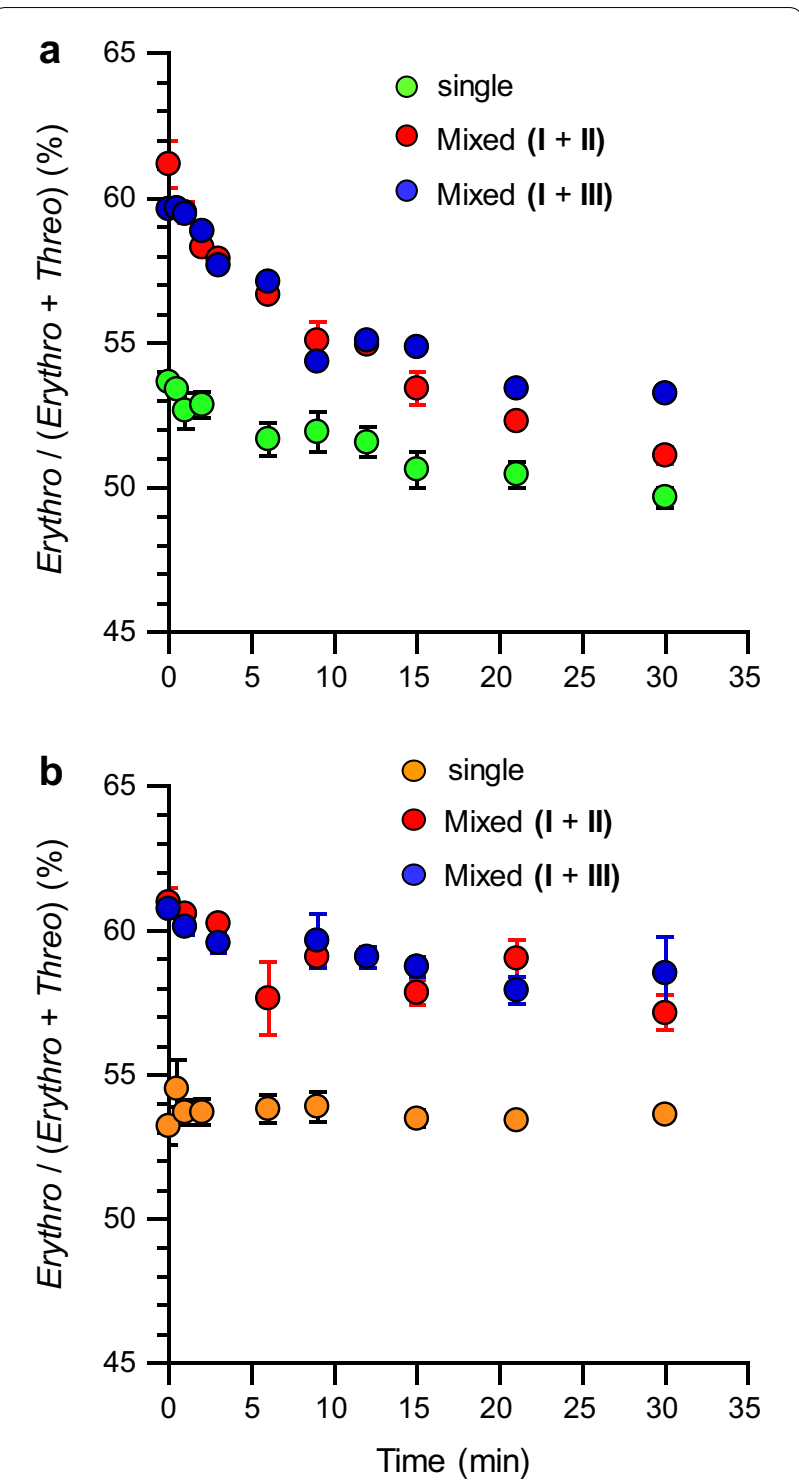

Fig. 3 Time course of erythro ratio of residual I in the single-component and mixed-component systems. a Using the crude enzyme, b using HRP

this study suggested that the reactivity of erythro form was slightly higher than that of threo form. On the other hand, in the water-addition reaction to quinone methide of I, completely opposite result was shown recently, where threo was preferentially formed more than erythro [17]. The recent study and our experiment were conducted in vitro, and thus may not perfectly be a mimic of lignin biosynthesis. Further study should be needed to give comprehensive consideration to lignin biosynthesis. 


\section{Conclusion}

- The polymerization behavior of dilignols in the presence of the crude enzyme obtained from Japanese cypress was similar to that observed with HRP, suggesting that radical transfer also occurred when using the crude enzyme.

- When using the crude enzyme, the reactivity of the erythro form of I was higher than that of the threo form, which implied that the crude enzyme showed substrate specificity toward erythro rather than threo forms. On the other hand, HRP does not have substrate specificity toward the erythro nor threo forms.

- During the radical transfer system, II and III radicals somewhat preferentially reacted with erythro form of I rather than the threo form.

\section{Additional file}

Additional file 1: Figure S1. Enzymatic activity of HRP and the crude enzyme against II. The unit shows the activity against guaiacol. Figure $\mathbf{S 2}$. Time course of residual ratio of the erythro and threo diastereomers of $\mathbf{I}$ in the single-component and mixed-component systems. (a, c) Using the crude enzyme, (b, d) using HRP dilignols, (a, b) mixed-component system $(\mathbf{I}+\mathbf{I I})$ within single-component system (b, d) mixed-component system (I+ III) within the single-component reaction le: erythro, It: threo. Figure S3. Display of conformation of erythro and threo isomers of I. A-ring and $\mathrm{O}-\mathrm{B}$-ring is located at Anti-position. The steric hindrance around the A-ring in erythro is less than that of in threo.

\section{Abbreviations}

HRP: horseradish peroxidase; PMSF: benzylsulfonyl fluoride; PVP: polyvinyl pyrrolidone; LC: liquid chromatography; RT: retention time.

\section{Acknowledgements}

This work was supported by the Japan Society for the Promotion of Science KAKENHI (Nos. $17 \mathrm{H} 03842$ and 18H03959).

\section{Authors' contributions}

YM mainly planned and analyzed data obtained in this research. YM was a major contributor in writing the manuscript. DB performed almost the experiments and also analyzed data obtained in this research. YM is a corresponding author. DA and KF also analyzed the data obtained in this research. All authors read and approved the final manuscript.

\section{Funding}

Not applicable.

\section{Availability of data and materials}

All data generated or analyzed during this study are included in this published article and its Additional file.

\section{Competing interests}

The authors declare that they have no competing interests.
References

1. Sasaki S, Nonaka D, Wariishi H, Tsutsumi Y, Kondo R (2008) Role of Tyr residues on the protein surface of cationic cell-wall-peroxidase (CWPO-C) from poplar: potential oxidation sites for oxidative polymerization of lignin. Phytochemistry 69:348-355

2. Shigeto J, Itoh Y, Tsutsumi Y, Kondo R (2012) Identification of Tyr 74 and Tyr177 as substrate oxidation sites in cationic cell wall-bound peroxidase from Populus alba L. FEBS J 279:348-357

3. Shigeto J, Kiyonaga Y, Fujita K, Kondo R, Tsutsumi $Y$ (2013) Putaive cationic cell-wall-bound peroxidase homologues in Arabidopsis, AtPrx2, AtPrx25, and AtPrx71, are involved in lignification. J Agric Food Chem 61:3781-3788

4. Hatfield RD, Vermerris W (2001) Lignin formation in plants. The dilemma of linkage specificity. Plant Physiol 126:1351-1357

5. Fournand D, Cathala B, Lapierre C (2003) Initial steps of the peroxidase-catalyzed polymerization of coniferyl alcohol and/or sinapyl aldehyde: capillary zone electrophoresis study of pH effect. Phytochemistry 62(2):139-146

6. Takahama U, Oniki T, Shimokawa H (1996) A possible mechanism for the oxidation of sinapyl alcohol by peroxidase-dependent reactions in the apoplast: enhancement of the oxidation by hydroxycinnamic acids and components of the apoplast. Plant Cell Physiol 37(4):499-504

7. Takahama U, Oniki T (1997) Enhancement of peroxidase-dependent oxidation of sinapyl alcohol by an apoplastic component, 4-coumaric acid ester isolated from epicotyls of Vigna angularis L. Plant Cell Physiol 38(4):456-462

8. Aoyama W, Sasaki S, Matsumura S, Mitsunaga T, Hirai H, Tsutsumi Y, Nishida T (2002) Sinapyl alcohol-specific peroxidase isoenzyme catalyzes the formation of the dehydrogenative polymer from sinapyl alcohol. J Wood Sci 48(6):497-504

9. Hatfield R, Ralph J, Grabber JH (2008) A potential role for sinapyl p-coumarate as a radical transfer mechanism in grass lignin formation. Planta 228:919-928

10. Hatfield RD, Marita JM (2010) Enzymatic processes involved in the incorporation of hydroxycinnamates into grass cell walls. Phytochem Rev 9:35-45

11. Westermark U (1982) Calcium promoted phenolic coupling by superoxide radical: a possible lignification reaction in wood. Wood Sci Technol 16:71-78

12. Önnerud H, Zhang L, Gellerstedt G, Henriksson G (2002) Polymerization of monolignols by redox shuttle-mediated enzymatic oxidation: a new model in lignin biosynthesis I. Plant Cell 14:1953-1962

13. Matsushita Y, Ko C, Aoki D, Hashigaya S, Yagami S, Fukushima K (2015) Enzymatic dehydrogenative polymerization of monolignol dimers. J Wood Sci 61:608-619

14. Matsushita Y, Okayama M, Aoki D, Yagami S, Fukushima K (2019) Radical transfer system in the enzymatic dehydrogenative polymerisation (DHP formation) of coniferyl alcohol (CA) and three dilignols. Holzforschung 73:189-195

15. Hiraide H, Yoshida M, Sato S, Yamamoto H (2016) In situ detection of lacasse activity and immunolocalisation of a compression-wood-specific laccase (CoLac1) in differentiating xylem of Chamaecyparis obtuse. Funct Plant Biol 43:542-552

16. Akiyama T, Goto H, Nawawi DS, Syafii W, Matsumoto Y, Meshitsuka G (2005) Erythro/threo ratio of $\beta$-O-4-structures as an important structural characteristic of lignin. Part 4: variation in the erythro/threo ratio in softwood and hardwood lignins and its relation to syringyl/guaiacyl ratio. Holzforschung 59:276-281

17. Zhu X, Akiyama T, Yokoyama T, Matsumoto Y (2019) Lignin-biosynthetic study: reactivity of quinone methides in the diastereopreferential formation of $p$-hydroxyphenyl-and guaiacyl-type $\beta$-O-4 structures. J Agric Food Chem 67:2139-2147

\section{Publisher's Note}

Springer Nature remains neutral with regard to jurisdictional claims in published maps and institutional affiliations. 